\title{
A Candidate Pathway for a Visual Instructional Signal to the Barn Owl's Auditory System
}

\author{
Harald Luksch, Bärbel Gauger, and Hermann Wagner \\ Institut für Biologie II, Rheinisch-Westfälische Technische Hochschule Aachen, D-52074 Aachen, Germany
}

\begin{abstract}
Many organisms use multimodal maps to generate coherent neuronal representations that allow adequate responses to stimuli that excite several sensory modalities. During ontogeny of these maps, one modality typically acts as the dominant system the other modalities are aligned to. A well studied model for the alignment of sensory maps is the calibration of the auditory space map by the visual system in the optic tectum of the barn owl. However, a projection from the optic tectum to the site of plasticity in the auditory pathway that could deliver an instructive signal has not been found so far. We have analyzed the development of the connectivity between the bimodal (vi-
\end{abstract}

For adequate responses to sensory stimuli of different modalities, organisms have to generate a coherent representation of their environment that is often accomplished by multimodal maps (Stein and Meredith, 1993; Knudsen, 1999). During development, maps of different modalities have to be combined and calibrated onto the same frame of reference, a process that requires plasticity in the connections involved. The mechanisms underlying these processes are best studied in barn owl (Knudsen, 1999), ferret (King et al., 1998), guinea pig (Withington-Wray et al., 1990), and cat (Stein, 1998). The barn owl represents an especially well suited model for studying the developmental interaction of visual and auditory information, because both ears and eyes are almost immobile in the head, thus yielding a common headcentered coordinate system for both modalities (Knudsen, 1999).

In the barn owl optic tectum (OT), a bimodal (visual and auditory) map of space is found (Knudsen, 1982). The superficial layers of the OT receive a direct visual projection from the retina; additionally, the OT receives a topographic projection from the external nucleus of the inferior colliculus (ICX), where a map of auditory space exists (Knudsen and Konishi, 1978; Brainard and Knudsen, 1993). Experiments with prism-reared owls have shown that the visual system is the dominant modality for the alignment of both spatial representations; thus, the visual system calibrates the auditory map (Knudsen and Knudsen, 1985). Anatomical and physiological data indicate that, within the auditory pathway, the site of plasticity is the ICX (Feldman and Knudsen, 1997, 1998). Plastic changes include axonal outgrowth (DeBello et al., 1999), formation of new glutamatergic synapses (Feldman et al., 1996; Feldman and Knudsen, 1998), and GABAergic inhibition of old connections (Zheng and Knudsen, 1999).

\footnotetext{
Received Jan. 18, 2000; revised Feb. 15, 2000; accepted Feb. 17, 2000.

This work was supported by Deutsche Forschungsgemeinschaft Grants Lu 622 2-1 to H.L. and Wa 606 9-1 to H.W. We are grateful to Dr. A. Nieder, J. Lippert, and two anonymous reviewers for helpful comments on this manuscript.

Correspondence should be addressed to Dr. Harald Luksch, Institut für Biologie II, Rheinisch-Westfälische Technischen Hochschule Aachen, Kopernikusstrasse 16, D-52074 Aachen, Germany. E-mail: luksch@bio2.rwth-aachen.de.

Copyright (C) 2000 Society for Neuroscience $0270-6474 / 00 / 200001-\bullet \$ 15.00 / 0$
}

sual and auditory) map of space in the barn owl's optic tectum and the auditory space map in the inferior colliculus with tracing methods and intracellular fills. Neurons in the tectal stratum griseum centrale were found to be suited to deliver an alignment signal from the visual midbrain to the auditory pathway. These neurons are presumably part of the efferent tectal projection pathway that mediates head saccades. The implications of a sensory alignment signal possibly being delivered by a (pre)motor command pathway are discussed.

Key words: multimodal maps; optic tectum; superior colliculus; inferior colliculus; plasticity; development; premotor projections
Although an instructional signal from the visual to the auditory system is crucial for the alignment of both maps, the neuronal circuitry that delivers that signal (Fig. 1, arrow 3) has not been identified so far. Knudsen (1994) sketched three ways through which such a signal might be obtained: by having a retinotopically organized projection to ICX, by comparison of auditory and visual information and delivery of an error signal to the ICX, and by visual assessment of the accuracy of auditory-evoked orienting responses. We investigated the putative source of the calibration signal and the developmental occurrence of the circuitry with intracellular methods and different in vitro tracing protocols, including whole-brain and slice preparations. We focused on the neurons of the tectal stratum griseum centrale (SGC; layer 13), because neurons in this layer receive part of the efferent projection from the ICX (Feldman and Knudsen, 1997). Although the majority of SGC neurons constitute the ascending tectofugal pathway (Karten et al., 1997, Luksch et al., 1998), a small portion contributes to the descending crossed tectobulbar tract (CTB; Reiner and Karten, 1982), which is equivalent to the medial efferent pathway (Masino and Knudsen, 1992).

\section{MATERIALS AND METHODS}

Experiments were performed in an in vitro preparation. All procedures were approved by the Animal Care Committee of RheinischWestfälische Technische Hochschule Aachen and the Regierungsprä-

This article is published in The Journal of Neuroscience, Rapid Communications Section, which publishes brief, peerreviewed papers online, not in print. Rapid Communications are posted online approximately one month earlier than they would appear if printed. They are listed in the Table of Contents of the next open issue of JNeurosci. Cite this article as: JNeurosci, 2000, 20:RC70 (1-4). The publication date is the date of posting online at www.jneurosci.org.

http://www.jneurosci.org/cgi/content/full/4117 


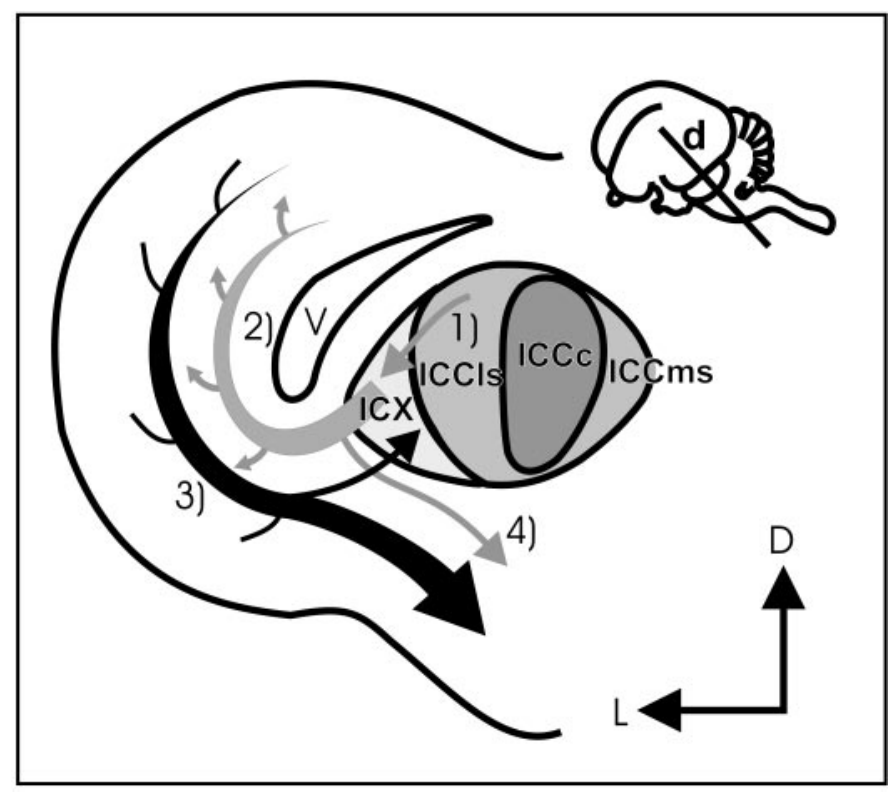

Figure 1. Barn owl midbrain structures involved in the formation of the bimodal map in the OT. Gray arrows show ascending projections from the lateral shell of the central nucleus of the inferior colliculus ( $\mathrm{ICCls})$ to the ICX (1) and from the ICX to the OT (2) and a collateral projection observed in ICX neurons with unknown target zone (4). The black arrow (3) depicts the presumed descending instructional signal from OT to ICX. $V$, Ventricle; ICCc, core of the ICC; ICCms, medial shell of the ICC. Inset, Schematic lateral view of an owl's brain with indication of the slice orientation (transversal to the long axis of the OT).

sidium Köln. Barn owl embryos of different developmental stages were deeply anesthetized with ketamine $(100 \mathrm{mg} / \mathrm{kg}$ body weight $)$ and decapitated. The brain was quickly removed and placed in cold sucrosesubstituted oxygenated artificial CSF (ACSF; $240 \mathrm{~mm}$ sucrose, $3 \mathrm{~mm}$ $\mathrm{KCl}, 3 \mathrm{~mm} \mathrm{MgCl} 2,1.2 \mathrm{~mm} \mathrm{NaH}_{2} \mathrm{PO}_{4}, 23 \mathrm{~mm} \mathrm{NaHCO}$, and $11 \mathrm{~mm}$ D-glucose). In the whole-brain tracing experiment [one animal at the day of hatch; embryonic day 32 (E32)] the telencephalon and the cerebellum were discarded, meninges were carefully removed, and the tectum was incised at the posterior pole. Small crystals of biotinylated dextran amine (BDA, $5000 \mathrm{kDa}$; Molecular Probes, Eugene, OR) were applied to the cut during brief removal of the preparation from the ACSF. The tissue was kept in $1000 \mathrm{ml}$ of ACSF ( $120 \mathrm{~mm} \mathrm{NaCl}, 3 \mathrm{~mm} \mathrm{KCl,} 1 \mathrm{~mm} \mathrm{MgCl}_{2}$, $2 \mathrm{mM} \mathrm{CaCl}_{2}, 1.2 \mathrm{~mm} \mathrm{NaH}_{2} \mathrm{PO}_{4}, 23 \mathrm{~mm} \mathrm{NaHCO}_{3}$, and $11 \mathrm{~mm}$ D-glucose) for $27 \mathrm{hr}$, continuously bubbled with Carbogen (95\% oxygen and 5\% $\mathrm{CO}_{2}$ ) at room temperature, and fixed afterward by immersion in $4 \%$ paraformaldehyde in phosphate buffer, $\mathrm{pH}$ 7.4.

For the intracellular and tracing experiments in the slice, brains were removed as before, the tectodiencephalic area was isolated, and slices of $500 \mu \mathrm{m}$ thickness were prepared transversally to the long axis of the optic tectum (Fig. 1, inset) with a vibratome (Vibroslice; WPI, Sarasota, FL). Slices were collected in oxygenated ACSF and kept submerged in a chamber continuously bubbled with Carbogen. To allow the identification of tectal layers under epifluorescent illumination, slices were incubated with $0.01 \%$ Acridin Orange (Molecular Probes). For intracellular labeling, slices were transferred to a custom-built submersion chamber on a fixed stage microscope (Axioskop FS; Zeiss, Oberkochen, Germany). We labeled cells of the tectal stratum griseum centrale in four barn owls [three E32 and one postnatal day 16 (P16)]. Neurons were impaled with intracellular electrodes $(100-180 \mathrm{M} \Omega, 0.5 \mathrm{M} \mathrm{K}$-acetate with $1 \%$ pyrenine; Molecular Probes; and 4\% biocytin; Sigma, Saint Louis, MO) mounted on a hydraulic microdrive (Narishige, Tokyo, Japan) and iontophoretically filled with biocytin with the iontophoreses unit of the amplifier (Duo 773, WPI). After filling, slices were kept in ACSF for at least $4 \mathrm{hr}$ to allow transport along the neurites before fixation. In nine animals (E14, three E16, E18, E26, E30, and two E32), the projection from the OT to the inferior colliculus (IC) was anterogradely labeled by application of small crystals of biotinylated dextran amine into the deeper layers of the OT (layers 10-14) at different positions within the tectal map. At

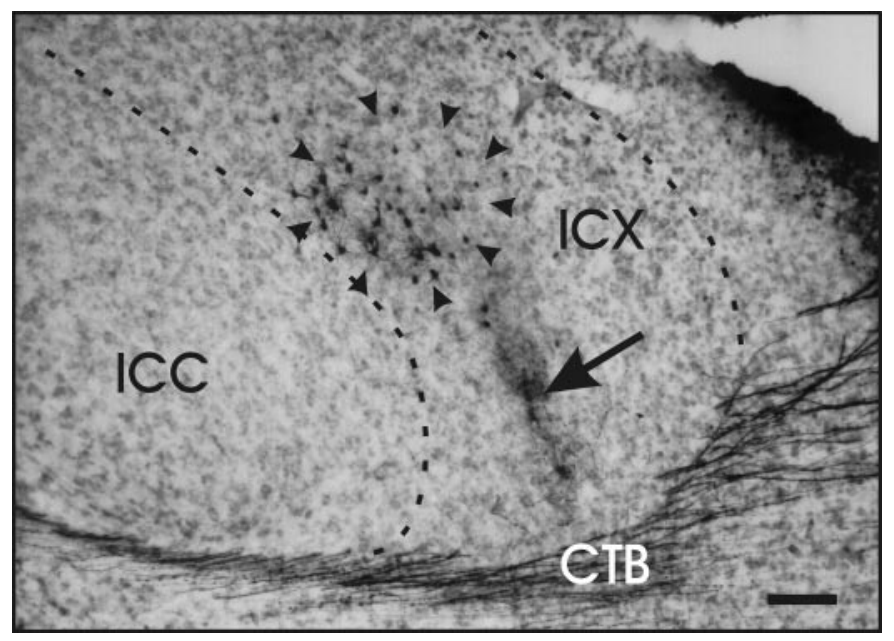

Figure 2. In vitro whole-brain tracing in an E32 animal. Transversal section gives an overview of anterogradely and retrogradely labeled somata and terminal structures within the ICX after application of BDA into the optic tectum. Most of the retrogradely labeled somata were located within the circle marked by arrowheads; stained terminal structures are marked by the arrow. Giemsa counterstain; scale bar, $100 \mu \mathrm{m}$.

least $4 \mathrm{hr}$ were allowed for transport. After fixation, brains and slices were sectioned on a cryostat at $60 \mu \mathrm{m}$, and the biocytin was visualized with a heavy-metal enhanced avidin-biotin complex protocol. Labeled structures were reconstructed manually under high magnification (40 or $100 \times)$ with a camera lucida.

\section{RESULTS}

\section{Whole-brain tracing}

In vitro whole-brain tracing proved to be an effective technique for the demonstration of short-range connectivity. Tissue degeneration (pyknotic somata) could not be observed, and labeled structures had a normal appearance. Application of BDA into the tectum led to intense labeling of cells and neurites in the vicinity (direct labeling zone in Fig. 2), as well as retrograde and anterograde filling of axons leaving the OT. Efferent fibers could be traced $\sim 10 \mathrm{~mm}$ and allowed a clear distinction of the three efferent projection systems of the optic tectum, i.e., the rostral, medial, and caudal efferent projections (Masino and Knudsen, 1992). In the ICX, terminal structures of these axons were found that could be attributed to the axons forming the medial efferent projection. Additionally, neurons afferent to the OT were retrogradely labeled as demonstrated by filled somata in the ICX. Figure 2 shows a section through the IC with labeled somata and terminals within the ICX. A slight segregation of labeled terminals and somata was found; the area of stained somata was located more dorsally than the terminal zone, but both areas overlapped considerably.

\section{Tracing in the slice}

The slice experiments further revealed that as early as E14, axons of OT neurons course along the stratum album centrale toward brainstem targets. From E18 on, fibers with terminal structures were found to innervate the area of the IC, which, at that stage, is not clearly delineated into the central nucleus of the inferior colliculus (ICC) and ICX. This pattern of innervation was consistently found in all later stages of owl development; a typical example in an E18 animal is shown in Figure 3. In later stages, the innervation shifted to the lateral aspects of IC and was mostly restricted to the ICX. This innervation could clearly be attributed 


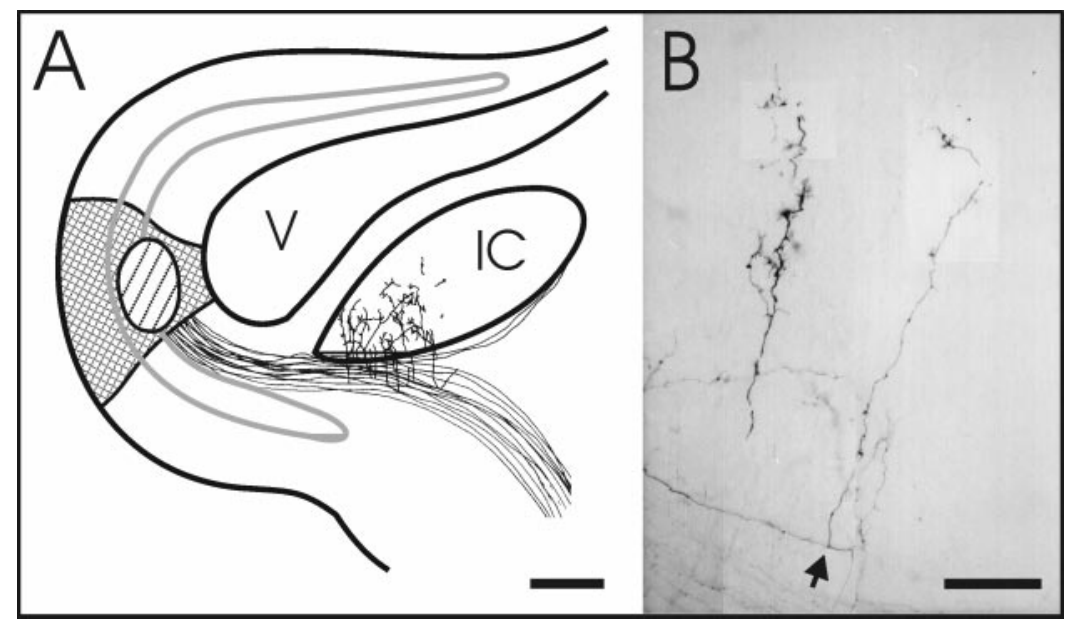

Figure 3. In vitro tracing in slices of an E18 animal. $A$, Schematic view of application site and projection along the CTB in a midbrain section. The SGC is outlined in light gray; $V$, ventricle; hatched area, application spot; cross-hatched area, region of direct labeling. At this stage the ICX cannot be clearly delineated within the IC. $B$, Details of efferent axonal structures within the IC of an embryo at E18. The arrow points to the bifurcation of the axon. The figure was digitally compiled from different focal planes. Scale bars: $A$, $250 \mu \mathrm{m} ; B, 50 \mu \mathrm{m}$.

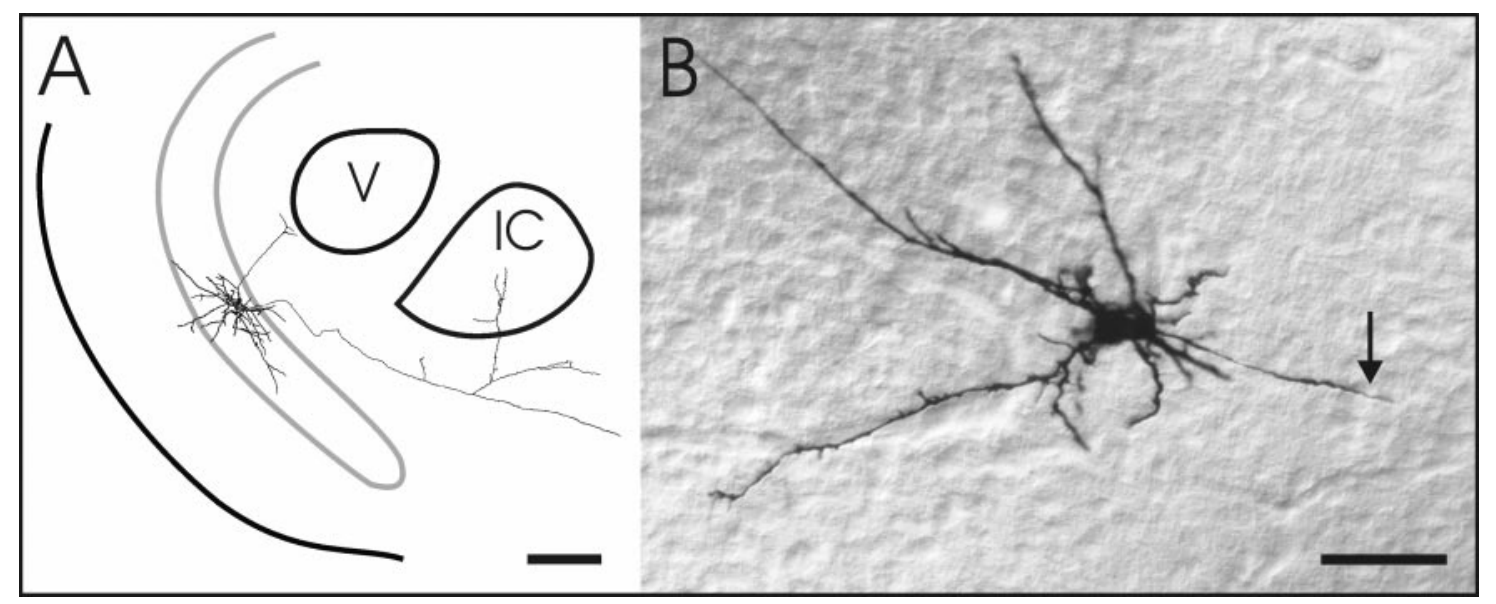

Figure 4. Intracellular fills of SGC neurons in midbrain slices. $A$, Reconstruction of an intracellularly labeled neuron projecting from OT to ICX and possibly the lateral shell of the ICC in an E32 animal. At this plane of sectioning, the IC consists almost entirely of ICX. $V$, Ventricle. $B$, Soma and neurites of an SGC neuron projecting to the ICX in differential interference contrast optics. The arrow indicates the axon. Scale bars: $A, 250 \mu \mathrm{m} ; B, 50 \mu \mathrm{m}$.

to tectal neurons and did not originate from indirect labeling of neurons afferent to both the OT and IC because, in the slice, most of these nuclei were cut off, and if contained, we never found retrogradely labeled somata. Closer examination of the fiber diameters within the IC revealed at least two classes of axons: thin-caliber (average $0.1 \mu \mathrm{m}$ ) and large-caliber (average $0.5 \mu \mathrm{m}$ ). Connectivity followed the topography of the space maps in the OT and ICX described in the adult owl; i.e., applications of tracer into the dorsal OT led to afferent labeling in the dorsal ICX, and ventral OT applications led to labeling in the ventral aspects of the ICX. Axonal structures found in the ICX were found to be collaterals of fibers that coursed along the crossed tectobulbar tract (Fig. $3 B$ ). Similar to the whole-brain tracing experiment, somata of ICX neurons were retrogradely labeled; however, the segregation of terminal zone and labeled somata in the ICX was less pronounced.

\section{Intracellular fills}

A total of 46 neurons were labeled intracellularly throughout the SGC. The majority of these neurons were positioned within the outer half of the SGC and had a characteristic morphology: cells were multipolar; the dendrites spanned large distances and eventually reached up toward the retinorecipient upper layers; and the distal dendritic tips displayed specialized input structures (bottlebrush endings). These cell types have recently been described in the chicken (Luksch et al., 1998) and project to the thalamic nucleus rotundus via the anterior efferent projection (Karten et al., 1997). Three of the SGC neurons (two E32 and one P16), however, had a different morphology: the multipolar neurons had rather small dendritic fields with dendrites that extended into all directions, including down toward the stratum album centrale, and did not reach into the retinorecipient tectal layers. The dendrites were smooth and did not have specialized structures at their distal tips. The axons of these neurons projected via the stratum album centrale into the crossed tectobulbar tract along the IC but could not be followed much further (Fig. 4). Beneath the IC, the axons gave off collaterals that invaded the IC and constituted terminal fields that were mostly restricted to the ICX. Fiber diameter of the SGC axons within the IC were of both caliber classes, indicating that both classes found in the tracing experiments might be attributable to the SGC. This projection was found in three of the four animals investigated and is thus already established at the time of hatch (E32).

\section{DISCUSSION}

We have shown that early in barn owl development the optic tectum sends a projection toward the IC that has topographic features. At E32 and P16, at least part of this projection is constituted by neurons of the SGC. Although we have not been 
able to delineate the additional axonal targets of these neurons, we suggest that these SGC neurons belong to the small subgroup that projects along the CTB. This assumption is based on several lines of evidence: (1) in their morphological features (soma size and multipolar organization with dendrites reaching into upper and lower tectal layers) these SGC neurons resemble the neurons that give rise to the CTB as described by Reiner and Karten (1982); (2) these neurons lack the dendritic specializations that are characteristic of the three SGC cell types from which the ascending projection in the chick arises (Luksch et al., 1998), although all of these cell types exist in the OT of the barn owl (H. Luksch, unpublished observations); and (3) the axons of these cells run within the CTB, give off collaterals that innervate the auditory midbrain, and continue with the CTB across the midline.

The finding that the tectal projection toward the auditory midbrain in barn owls arises from cells that project along the CTB has several implications. Masino and Knudsen (1992) demonstrated that the tectal neurons that constitute the CTB are important for the premotor control of head movements in response to auditory and visual stimuli (head saccades; du Lac and Knudsen, 1990). In respect to the issue of map alignment, this suggests that the instructive signal to the auditory space map is delivered by collaterals from neurons that innervate premotor centers in the midbrain and rhombencephalon.

The alignment of the bimodal tectal map by a premotor signal that is dominated by the visual system might be a simple and economical solution, because preexisting circuitry can simply be extended. Essentially, the system appears to be connected such that an SGC neuron that projects toward premotor targets gives off a collateral to the ICX that innervates a position within the auditory space map that is in register with the position of the cell within the combined map of space in the tectum. If (because of changes in the sensory periphery) conflicting space information reaches the tectum, the response of the SGC would be dominated by the visual input, leading to excitation at the "correct" position within the ICX where sustained excitation combined with a simple Hebbian learning rule could account for the plastic changes observed.

We have shown that as early as E18, neurons of the optic tectum project toward the IC in barn owl embryos. At E32 and $\mathrm{P} 16$, at least part of this projection arises from neurons of the SGC. The early establishment of this projection is somewhat surprising, because the precise alignment of sensory maps can only start after eye opening (at $\sim \mathrm{P} 12$ ). This finding is less surprising, however, if the premotor nature of this projection is considered. (Pre)motor connectivity is established early in development; e.g., in chicken eye movements can be detected after one-third of embryonic development (Rogers, 1995).

The neuronal circuitry we found is retinotopically organized and very likely carries a visually dominated premotor response command, thus substantiating the first mechanism for auditory map alignment envisioned by Knudsen (1994). However, map alignment might additionally be influenced by telencephalic afferents from, e.g., the archistriatal gaze field (Knudsen et al., 1995) and the auditory archistriatum (Cohen et al., 1998). Moreover, recent data (Hyde and Knudsen, 2000) indicate an additional projection from tectal layers $\mathrm{h}-\mathrm{j}$ of the stratum griseum and fibrosum superficiale to the IC. These neurons are known to contribute to the ipsilateral tectobulbar tract (Reiner and Karten, 1982) that projects to the rhombencephalic reticular nuclei, implying a nonmotor function of this projection (Masino and Knudsen, 1992).

The alignment of space maps of different sensory modalities in the visual midbrain is a developmental process common to all vertebrates (King, 1999). Recent anatomical studies (Baron et al., 1998) have demonstrated that the mammalian superior colliculus sends a projection to the inferior colliculus, the source of its auditory input, suggesting that neuronal circuitry analogous to our findings exists in the midbrain of mammals as well.

\section{REFERENCES}

Baron J, Doubell TP, King AJ (1998) Back projection from the superficial layers of the ferret superior colliculus to its primary source of auditory input in the inferior colliculus. Soc Neurosci Abstr 24:1882.

Brainard MS, Knudsen EI (1993) Experience-dependent plasticity in the inferior colliculus: a site for visual calibration of the neural representation of auditory space in the barn owl. J Neurosci 13:4589-4608.

Cohen YE, Miller GL, Knudsen EI (1998) Forebrain pathway for auditory space processing in the barn owl. J Neurophysiol 79:891-902.

DeBello WM, Feldman DE, Cheng KD, Knudsen EI (1999) Visual experience alters the axonal topography of auditory neurons in barn owl inferior colliculus. Soc Neurosci Abstr 25:1417.

du Lac S, Knudsen EI (1990) Neural maps of head movement vector and speed in the optic tectum of the barn owl. J Neurophysiol 63:131-149.

Feldman DE, Knudsen EI (1997) An anatomical basis for visual calibration of the auditory space map in the barn owl's midbrain. J Neurosci 17:6820-6837.

Feldman DE, Knudsen EI (1998) Pharmacological specialization of learned auditory responses in the inferior colliculus of the barn owl. J Neurosci 18:3073-3087.

Feldman DE, Brainard MS, Knudsen EI (1996) Newly learned auditory responses mediated by NMDA receptors in the owl inferior colliculus. Science 271:525-528.

Hyde PS, Knudsen EI (2000) Topographic projection from the optic tectum to the auditory space map in the inferior colliculus of the barn owl. J Comp Neurol, in press.

Karten HJ, Cox K, Mpodozis J (1997) Two distinct populations of tectal neurons have unique connections within the retinotectorotundal pathway of the pigeon (Columba livia). J Comp Neurol 387:449-465.

King AJ (1999) Sensory experience and the formation of a computational map of auditory space in the brain. Bioessays 21:900-911.

King AJ, Schnupp JW, Thompson ID (1998) Signals from the superficial layers of the superior colliculus enable the development of the auditory space map in the deeper layers. J Neurosci 18:9394-9408.

Knudsen EI (1982) Auditory and visual maps of space in the optic tectum of the owl. J Neurosci 2:1177-1194.

Knudsen EI (1994) Supervised learning in the brain. J Neurosci 14:3985-3997.

Knudsen EI (1999) Mechanisms of experience-dependent plasticity in the auditory localization pathway of the barn owl. J Comp Physiol [A] 185:305-312.

Knudsen EI, Knudsen PF (1985) Vision guides the adjustment of auditory localization in young barn owls. Science 230:545-548.

Knudsen EI, Konishi M (1978) A neural map of auditory space in the owl. Science 200:795-797.

Knudsen EI, Cohen YE, Masino T (1995) Characterization of a forebrain gaze field in the archistriatum of the barn owl: microstimulation and anatomical connections. J Neurosci 14:5139-5151.

Luksch H, Cox K, Karten HJ (1998) Bottlebrush dendritic endings and large dendritic fields: motion detecting neurons in the tectofugal pathway. J Comp Neurol 396:399-414.

Masino T, Knudsen EI (1992) Anatomical pathways from the optic tectum to the spinal cord subserving orienting movements in the barn owl. Exp Brain Res 92:194-208.

Reiner A, Karten HJ (1982) Laminar distribution of the cells of origin of the descending tectofugal pathways in the pigeon (Columba livia). J Comp Neurol 208:165-187.

Rogers LJ (1995) The development of brain and behavior in the chicken. Wallingford, UK: CAB International.

Stein BE (1998) Neural mechanisms for synthesizing sensory information and producing adaptive behaviors. Exp Brain Res 123:124-135.

Stein BE, Meredith MA (1993) The merging of the senses. Cambridge, MA: MIT.

Withington-Wray DJ, Binns KE, Keating MJ (1990) The developmental emergence of a map of auditory space in the superior colliculus of the guinea pig. Dev Brain Res 51:225-236.

Zheng W, Knudsen EI (1999) Functional selection of adaptive auditory space map by GABA-mediated inhibition. Science 284:962-965. 